\title{
Social capital undergirds coping strategies: evidence from two informal settlements in Nairobi
}

\author{
Desire Mpanje ${ }^{1^{*}} \mathbb{D}$, Pat Gibbons ${ }^{1}$, Ronan McDermott ${ }^{1}$, Dalmas Ochieng' Omia ${ }^{2}$ and Charles Owuor Olungah ${ }^{2}$
}

\begin{abstract}
Understanding the nature and scope of existing social capital is essential to building the resilience of people living in vulnerable urban settings. This paper explores the question of how aid organisations can better utilise social capital to build the resilience of communities in slums. It specifically examines the relationship between social capital and urban vulnerability. The study used a mixed-methods approach to understand the diverse perspectives of social capital and uncover relationships that exist between social capital, absorptive and adaptive coping strategies in Kibera and Kawangware slums in Nairobi, Kenya. The findings show that coping is not a community or a societal issue; people living in slums resort to either absorptive or adaptive coping strategies or a combination of both due to the precariousness of livelihoods in such contexts. Measures of bonding, bridging, and linking social capital in slums are significantly associated with adaptive coping strategies. Families that had more dependents, were taking care of ill members or that had no regular source of income were more likely to resort to withdrawing children from school, begging, selling assets, amongst others. Livelihood studies overlook critical aspects of social capital such as bridges and linkages, which are essential for building the transformative capacities of slum dwellers. Therefore, aid actors should focus on social capital if they are to build the capacities of people living in slums. More attention should be given to the role of local organisations and initiatives in establishing bridges and linkages so as not to undermine communities' existing capacities and resource base.
\end{abstract}

Keywords: Bonding, Bridging, Linking, Social capital, Slums, Urban vulnerability, Absorptive coping strategies, Adaptive coping strategies, Kibera, Kawangware

\section{Introduction}

Urbanisation, driven by a range of competing factors, including natural population growth, rural-urban migration, and displacement, presents an enormous challenge to already poorly serviced cities (Mpanje et al. 2018; Parker and Maynard 2015). More than one billion people live in informal urban settlements, $90 \%$ of which are found in developing and middle-income countries (UNFPA 2015; NRC and IDMC 2015; Hope Sr. 2012).

\footnotetext{
*Correspondence: mpanjedesire@gmail.com

${ }^{1}$ Centre for Humanitarian Action, School of Agriculture and Food Science, University College Dublin, Belfield Campus, Room G-05, Dublin 4, Dublin, Ireland

Full list of author information is available at the end of the article
}

Evidence suggests that humanitarian crises of the future are likely to be in urban with all the attendant systemic complexity that cities present (Parker and Maynard 2015; WHS Secretariat 2015). This sentiment is supported in recent global policy documents including the Sendai Framework for Disaster Risk Reduction 2015-2030; Sustainable Development Goals; World Humanitarian Synthesis Report - October 2015 (World Humanitarian Summit \{WHS\} Secretariat 2015); UN-Habitat 2016 and the IFRC World Disasters Report 2016. The urban complexity requires a greater awareness of societal/ social systems and demands approaches that acknowledge the dense interconnectedness already present in such urban areas. This highlights the importance of understanding 
social capital and its role in undergirding coping capacities within urban settings.

Social capital is a widely deployed concept within the social sciences and has been identified as a key to overcoming vulnerabilities (Natcher 2015; Amendah et al. 2014; Gallaher et al. 2013; Dean et al. 2011; Misselhorn 2009; Martin et al. 2004). For the purposes of this article, social capital is understood as

"The institutions and relationships that shape the quality and quantity of social interactions in vulnerable urban settings, which in the end enhance individual, community and society's capacity to collaborate in the achievement of both individual and collective aims before, during, and after a humanitarian crisis" (Mpanje et al. 2018, p.3).

Social capital consists of relationships and connections that exist between and amongst individuals, groups, and institutions. Such relationships and connections are embedded in three forms of social capital: bonding, bridging, and linking capitals (Aldrich et al. 2020; Mpanje et al. 2018; Álvarez and Romaní 2017). Bonding capital refers to personal relations based on a sense of collective identities such as family, close friendship, and sharing the same culture or ethnicity. It encompasses the norms of trust $^{1}$ and the norms of reciprocity (Aldrich et al. 2020; Mpanje et al. 2018; Álvarez and Romaní 2017). Bridging capital concerns peoples' relations or links that stretch beyond a shared sense of identities, such as distant friends, colleagues, and associates; these connections tend to be used for common aims. On the other hand, linking capital refers to the relationships between individuals and groups and formal institutions and systems such as security, education, governance, and the economy. In other words, linking capital concerns the connections of people with power, influence, and resources (Aldrich et al. 2020; Mpanje et al. 2018; Álvarez and Romaní 2017).

This paper explores the question of how aid organisations dealing with urban vulnerable communities can better utilise the existing social capital to cope in times of need. While the vulnerability is not always associated with the urban poor, there is a broad overlap between poverty and vulnerability within the urban setting. Gallaher et al. (2013) found that people living in

\footnotetext{
${ }^{1}$ Literature identifies three types of trust (Cook 2001; Smith 2010; Paliszkiewicz 2011; Mpanje et al. 2018) namely-(a) generalised trust, a kind of trust that is based largely on social learning; (b) particularised trust, the idea that people 'like me' can be trusted, but that other groups may not share my moral values; and (c) strategic trust, the idea that specific others have the appropriate motives and intentions and can be relied upon to act in one's interests in specific situations and around specific issues.
}

Kibera slums who had higher social capital levels were more food secure. Moreover, authors such as Dean et al. (2011) and Martin et al. (2004) argue that households of low-income communities with high social capital levels are less likely to experience hunger. In the same vein, Amendah et al. (2014) suggest that people with strong networks of relatives and friends are less likely to resort to negative coping strategies in times of need. Their argument is consistent with Misselhorn (2009) who posits that social capital was an essential dimension of well-being in communities in KwaZulu Natal, South Africa, and therefore should be considered in vulnerability mapping systems.

However, Natcher (2015) identifies a "dark side" of social capital and posits that households with limited social capital to draw on in times of crisis or need may be susceptible to social exclusion and other vulnerabilities. It has also been suggested that high levels of social capital can be misappropriated and lead to adverse outcomes such as the emergence of gang violence (Villalonga-Olives and Kawachi 2017). Such adverse outcomes of social capital would be counterproductive when addressing the needs of people living in vulnerable urban contexts.

The paper aims to advance the understanding of how aid organisations can build on the existing social capital to promote communities' resilience in informal urban settlements. The specific objectives are threefold: a) to identify the main vulnerability issues and associated coping mechanisms in selected informal urban settlements b) to ascertain the role of social capital in addressing critical urban vulnerabilities, and c) to propose how organisations should build on existing potential social capital in their programming. Ultimately, the paper provides evidence-based recommendations on how aid actors can build on existing social capital to address vulnerabilities and promote resilience in informal urban settlements.

\section{Social capital, urban livelihood and coping mechanisms}

Chambers and Conway (1992) describe livelihoods as comprising the capabilities, assets (social, economic, physical, natural, and human) and activities required for a means of living. Carney $(1998$, p4) goes further and states that:

"a livelihood is sustainable when it can cope with and recover from stresses and shocks and manage to enhance its capabilities and assets both now and in the future, while not undermining the natural resource base."

Livelihoods in urban contexts are highly monetised and defined in large part by the opportunities (e.g. access 
to markets, credit facilities) and constraints (e.g. lack of information, assets, sustainable income) under which they operate, which makes it imperative to understand the vulnerabilities of the urban context in question (Mpanje et al. 2018; Rakodi and Lloyd-Jones 2002). Informal urban settlement dwellers are vulnerable to various stresses and shocks such as food insufficiency, lack of access to clean water, inadequate housing, and income insecurity due to the contexts' informal nature. Nevertheless, the coping mechanisms employed to deal with such stresses and shocks vary depending on the capabilities and the assets available in the urban setting in question. Researchers agree that the urban poor often are forced to take out high-interest loans, sell assets, or engage in risky behaviour, to lessen exposure to extreme shocks and stresses because they have little or no access to formal sources of credit, private insurance against risk, or social insurance (Concern Worldwide and USAID 2014; Jha et al. 2013). Households also resort to using more coping strategies, such as reducing expenditure by removing children from school or attempting to increase incomes by sending children to work. It is not surprising that various theoretical interpretations of urban vulnerability have highlighted the importance of social capital, especially the network of support and reciprocity that may exist within and between households and with communities that people can call on in times of need (Natcher 2015; Chhabra et al. 2014).

Coping strategies are understood as conscious, rational approaches to dealing with the anxieties encountered in life (Reber 1985). They can be divided into an active strategy on the one hand and avoidance or passive strategies on the other (Sahler and Carr 2009; Bardwell et al. 2001). Coping involves maintaining the quality of life, such as better food consumption, health, and livelihood security of oneself or other household members (Usfar 2002). The choice of the coping strategies to rely upon depends on a range of endogenous factors (household socio-economic and demographic characteristics) and exogenous factors (the type of stress and shocks, e.g. economic, social, climate, civil strife amongst others). Coping strategies in the context of informal urban settlements can be divided between coping strategies that serve to absorb shocks and stressors on the one hand and those coping strategies that are undertaken to pro-actively adapt to such shocks and stressors (Amendah et al. 2014; Bené et al. 2014; Misselhorn 2009). The absorptive coping strategies can be likened to "resistance" since the households resist the shocks by changing the food diets and adaptive coping strategies as incremental adjustment since they diversify the means for survival (Matyas and Pelling 2014). While the nature of such coping strategy is contextspecific, absorptive coping strategies (AbCS) refer to conscious adjustments to existing livelihood practices. They include reducing the size or number of meals consumed by a household and consuming non-preferred food. Adaptive coping strategies (AdCS) refer to changed livelihood practices forced on the household due to a shock or stressor. Examples of adaptive coping strategies include selling assets, obtaining food on credit, begging, or removing a child from school. However, those amongst the extreme poor with low social capital may not possess savings or assets which they can dispose of in times of need (Anderson 2011; Maxwell and Caldwell 2008). As such, they survive by relying on relatives, friends, and sometimes resort to using a high number of coping strategies (Aldrich et al. 2020) to cope with stresses and shocks.

The multisectoral and multi-dimensional nature of social capital has resulted in scholars, organisations, and agencies ascribing disparate meanings of social capital in line with social relations, connections, social networks, social assets, and civic engagement. Nevertheless, Mpanje et al. (2018) propose a multi-level and multidimensional conceptual framework to capture social capital's complexity in vulnerable urban settings (Fig. 1).

They argue that social capital analysis should encompass quantitative and qualitative measures of bonding, bridging, and linking social capital to understand how social capital contributes to addressing the existing vulnerabilities. Emphasis is also placed on the importance of attending to the scale and level of analysis at which social capital operates. The framework foresees the use of context-specific indicators that are locally accepted and relevant and appropriate to the informal urban settlement's socio-economic and cultural factors being studied. In line with the framework of this study, the social capital determinants comprised of bonding social capital variables (i.e. low household level dependency, household size, interpersonal relationships, reciprocity) and linking social capital variables (i.e. years lived in the slum, education level of the primary income earner, household tenure security and source of income). Such variables have been proposed and/or used previously in other social capital, and coping strategies studies see, for example Amendah et al. (2014), and Aldrich et al. (2020). For the operational definitions of the social capital, variables see supplementary data 1 .

\section{Vulnerabilities and associated coping strategies in Kibera and Kawangware slums}

Kenya has been rapidly urbanising for the past decade, with half of the population living in urban centres (UNHabitat 2011; Beyer et al. 2016). It is estimated that more than half of Kenya's urban residents live in poverty, with meagre incomes, and often in unsanitary and overcrowded conditions on the peripheries of urban areas (Mukeku 


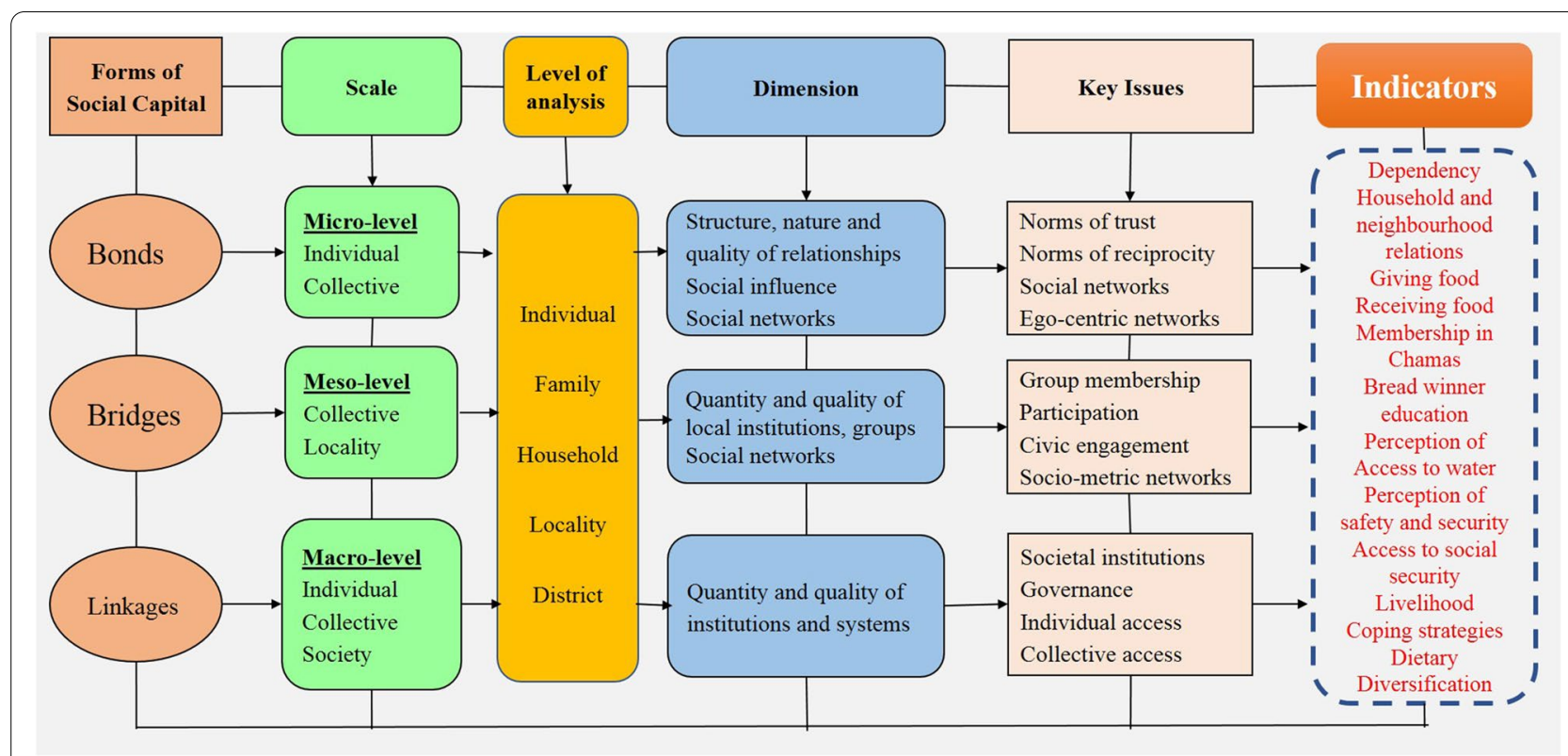

Fig. 1 Social capital conceptual framework adapted from Mpanje et al. (2018) demonstrating the use of context-specific indicators

2018; Beyer et al. 2016; Abdulla et al. 2011). Nairobi alone is believed to be home to $45 \%$ of Kenya's urban population, of which $60 \%$ live in slums on $4 \%$ of the city's land (UNHabitat 2011). Kibera is the biggest slum in Africa and one of the largest in the world. Kibera, which measures around $225 \mathrm{ha}$, is situated on the outskirts of Nairobi had a resultant density of 2222 people per hectare (with a population estimated to be in the range of 500 thousand to 1 million) of which roughly $95 \%$ of the households live below the poverty line (Kenya's Census ${ }^{2}$ 2019; Mukeku 2018; Concern Worldwide and USAID 2014). During the qualitative data collection, one of the participants indicated that the original settlers in Kibera were the Nubian people from the Kenyan and Sudanese borders. It was also learnt from the qualitative findings that the Kibera slum is divided into two parts, the upper area, which is the original Nubian settlement of Makina, and the lower area that has been densely settled during the last two decades. The baseline survey conducted by the IDSUE project in June 2015, indicates that the average household monthly income in Kibera was at about Ksh 7400 (approximately €60) with the majority of households (52.6\%) depending on casual labour as their primary source of livelihood. Kibera also has a significant proportion of severely hungry households (10\%). Cases of insecurity arising from tribal and election-related clashes are common. For example, in the $2007 / 8$ post-election

\footnotetext{
2019 Kenya Population and Housing Census Volume I: Population by County and Sub-County
}

violence witnessed in Kenya, Kibera was one of the conflict hotspots identified for its security operations.

On the other hand, Kawangware which is located about $15 \mathrm{~km}$ west of the centre of Nairobi, is one of the fast-growing and poorest slums in the City, with an ethnically diverse population of over 300,000, of which $65 \%$ are children and youth ${ }^{3}$ (Pamoja Trust 2009; Kenya's Census 2019). The people in Kawangware are mainly from the tribes of Kikuyu, Kisii, Kamba, Luo, and Nubian. Participants of the focus groups indicated that unlike Kibera, where the government owns the land, in Kawangware at least some people have land title deeds recognised by the government. Just like any other slums, over $50 \%$ of the adult population has no permanent job, limited access to education, and survive on less than one dollar a day. Safe drinking water in Kawangware is scarce and expensive. Water supplied by the city authority is not available every day. Waterborne diseases, respiratory pneumonia, aspiratory pneumonia and malaria are prevalent and airborne diseases due to the poor drainage system. Daily livelihood is characterised by running small businesses like hawkers (selling groceries, vegetables, clothes, shoes, etc.). Participants to the focus

\footnotetext{
3 There is huge uncertainty regarding the population figures for most of the slums in Nairobi, for example some literature indicates that in 1999 the population for Kawangware was over 200000 see for example Martin, R. \& Mathema, A. (2009). Development poverty and politics: Putting communities in the driver's seat. Development Poverty and Politics: Putting Communities in the Driver's Seat. 1-289. 10.4324/9780203862087.
} 


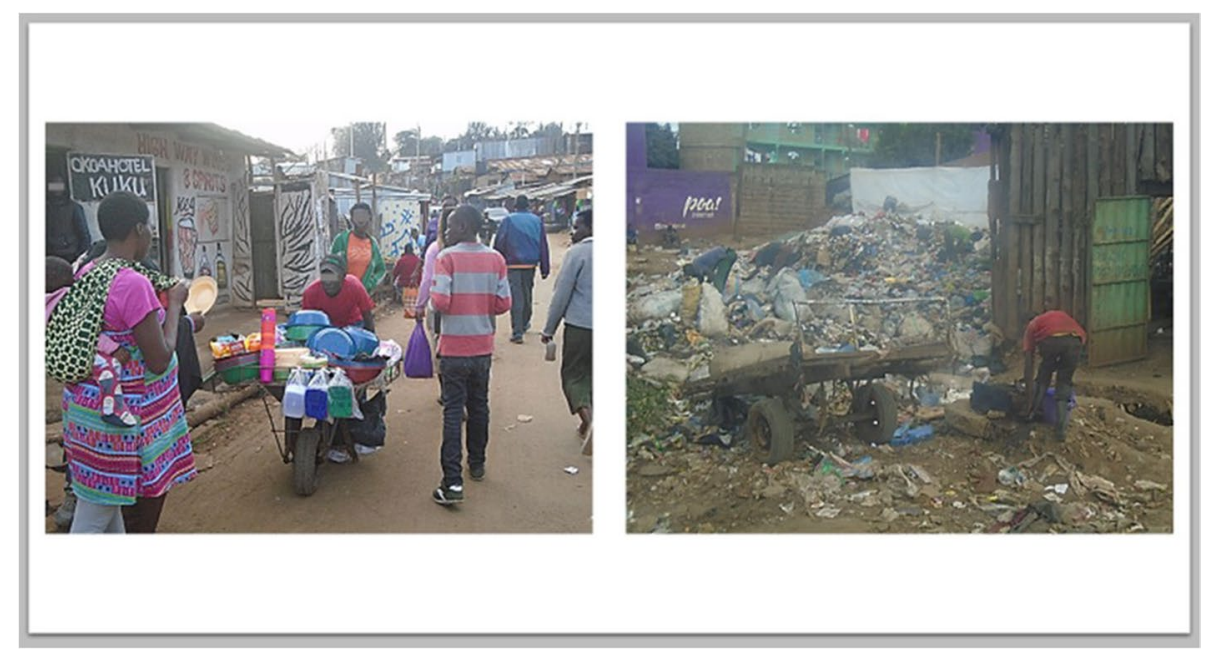

Fig. 2 Pettey trading and scavenging are some of the sources of income in the slums as demonstrated in this picture

groups indicated that many of the residents, especially men, work as casual labourers or work in the Jua-kali ${ }^{4}$ sector with minimum daily wages of about $€ 1$ sometimes less (Fig. 2).

In Kawangware the water taps scarcely have running water, forcing residents to obtain water from neighbouring villages or buy from trucks. Typical of slum settings, people relay on informal water markets where the charges are often very high, and the quality can be poor (Sarkar 2020). As mentioned by the focus groups participants, water purchase can cost up to 12 Kenyan Shillings $(€ 0.10)$ per $20-\mathrm{L}$ Jerrycan. Also, food, waste management are the main problems people face in Kawangware. Also, poor drainage is a serious problem since, according to the participants of the qualitative methods, landlords do not care about the hygiene and sanitation facilities of their properties. These findings are well detailed in the Results section.

\section{Research approach and methodology}

The study utilised part of the quantitative data collected under the Indicator Development for Surveillance of Urban Emergencies (IDSUE) programme. ${ }^{5}$ The IDSUE

\footnotetext{
${ }^{4}$ This is the informal economic sector in Kenya largely associated with artisanal industry, small scale traders, welders, small automobile shops and garages, and the broader group of people who get paid on a daily basis from a variety of menial jobs. The income generated in Jua kali sector is least formal and not based on a monthly paycheck.

${ }^{5}$ IDSUE study was funded by United States Agency for International Development's (USAID) Office of U.S Foreign Disaster Assistance (OFDA). The African Population and Health Research Centre (APHRC) in partnership with Concern Worldwide implemented the study with the aim of developing early warning indicators to identify slow-onset humanitarian emergencies in urban slums. Several baseline surveys and rounds of surveillance were conducted in the informal settlements in Nairobi (Kibera,
}

study responded to the need for more disaggregated data in slums to identify the threshold whereby chronic poverty tips into an urban emergency. The IDSUE study was conducted in the slums of Nairobi from the year 2012 to 2015 . The data used in this study was collected in 2015. IDSUE survey employed a stratified random sampling technique using a probability proportionate to estimated size (PPES). Through random sampling, each household had a fair probability of participating in the study. Therefore, it is laudable to assume the representativeness of a sample and the ability for the findings of the study to be generalised to the population. To determine appropriate sample size, four main steps were followed: mapping of settlement and village boundaries, stratification-segmentation and sub-segmentation of each village, counting and listing of households, and calculation of sample size. The marking of the boundaries of the two slums was through the Geographical Information System (GPS) tool. Maps were drawn using ArcGIS or QGIS software, with a clear settlement, village, and sub-segment boundaries. Once the households were listed, they were randomly selected until the number of households targeted from the segment was reached. The number of households sampled in each sub-segment was calculated proportionally to the village's total household number. The inclusion criteria

\footnotetext{
Footnote 5 (continued)

Eastleigh, Kawangware, Viwandani and Mukuru) in partnership with Kenya Red Cross Society (KRCS) and World Vision Kenya (WVK) in informal settlements in Mombasa (Bangladesh and Moroto). For more details on the urban surveillance study see Concern Worldwide - Indicator Development for Surveillance of Urban Emergencies-IDSUE Project Research reports.
} 
were that the respondent had to be at least a head of the household (male or female), a spouse, or adult at least 18 years old. Children and minors, especially vulnerable, were excluded based on the participants' judgement, using evidence from the organisations and brief conversations. Anybody who had previously worked or had a personal relationship with any of the researchers was also excluded from the survey. A total of 735 households (375 in Kawangware and 360 in Kibera; $79 \%$ maleheaded, and $21 \%$ female-headed in total) were surveyed based on the questionnaire uploaded on the Open Data Kit (ODK) platform. The response rate was $91 \%$.

This study employed the Coping Strategies Index (CSI) to measure coping methods in times of stress and shocks (Maxwell and Caldwell 2008). The indicator scores were then mapped to social capital variables to establish the influence of social capital on the use of AbCS and AdCS. The social capital variables were related to bonding and linking capital (see supplementary data 1). Therefore, to learn how households cope with food insecurity, the study identified a range of coping behaviours reported by the respondents to create an index based on universally agreed coping strategies. The CSI is built around a central question - what do you do when you do not have enough food or enough money to purchase food and how frequently do you do this? The logic is that when households are faced with food shortfalls, they will engage in behavioural choices linked to social, economic, and cultural factors (Anderson 2011; Maxwell and Caldwell 2008). Based on household scores using the CSI, the researchers constructed a binary variable to establish whether the respondents had either used greater or fewer than five coping strategies in the 4 weeks prior to administering the survey (see supplementary data 1 ). Descriptive statistics were used to map the existing vulnerabilities, and the results were disaggregated according to the settlement. The AdCS were then aggregated into a single continuous variable to determine the extent of their use across the two study areas. Linear logistic regression reporting coefficients were run to assess the correlation between social capital (bonding and linking capital) variables on the one hand, and the number of coping strategies on the other. The logistic regression presumed an equal value for each adaptive coping strategy. This aggregation of quite diverse AdCS into a single continuous variable might have masked each coping strategy's importance. The variables for social capital used in this study were specific but culturally and politically suited to the context (see supplementary data 1). Nonetheless, some of them have been used in other studies elsewhere, for example in Uganda and Nigeria (Aldrich et al. 2020), in Canada (Kitchen et al. 2012), and in South Africa (Misselhorn 2009).

\section{Covariates used in the analysis of the quantitative data}

A covariate is any variable that is measurable and considered to have a statistical relationship with the dependent variable (Salkind 2010). A covariate is thus a possible predictive or explanatory variable of the dependent (outcome) variable. For this research study, age, marital status, primary income earner education, income source, dependency ratio, household population, number of income earners, years lived in the settlement, and household occupancy mode were used as covariates. Age was a continuous variable. Respondent marital status was dichotomised into married (1) or not married (0). A single question assessed primary income earner education level and the household member's highest level of education. There were six categorical response options 1 (never attended school), 2 (elementary [class 1-8]), 3 (some high school [class 9-11]), 4 (high school graduate), 5 (some college or technical training), and 6 (college graduate or higher). Household population (and dependency ratio) was obtained by asking about the number of people that live in the household indicating their ages to determine dependency status. Income data were collected by asking if there is any household member who has earned any income in the last four weeks, or if there is a person doing anything to enable him/her to earn some income. There were eight categorical response options for the main source of income which was later narrowed to the main source of income - 1 (monthly salary), 2 (casual labour), 3 (hawking), 4 (remittances), 5 (scavenging), 6 (safety nets), 7 (stable business), and 8 (others specify).

\section{Qualitative methods}

In keeping with the mixed-methods research approach, phenomenological qualitative research was implemented as part of Preparedness and Resilience to address Urban Vulnerabilities (PRUV) $)^{6}$, a broader research project also conducted within the informal urban settlements of Kibera and Kawangware in Nairobi. The researchers collected qualitative data on social capital to obtain a richer understanding of the main vulnerabilities and explore social capital's role in addressing such vulnerabilities from the residents of the informal urban settlements. The study's phenomenological qualitative component helped explore the social capital and

\footnotetext{
${ }^{6}$ The PRUV project-a Horizon 2020 Rise Project, was made up of a wide array of organisations across Europe and the Global South: Centre for Humanitarian Action, University College Dublin; Concern Worldwide; Future Analytics Consulting; Plan International; Institute for International Law of Peace and Armed Conflict, Ruhr University Bochum; Globalisation Studies Groningen, University of Groningen; Human Rights Institute, University of Deusto; Center for Reproductive Health, Gadjah Mada University; The Institute for Anthropology, Gender and African Studies, University of Nairobi; Yayasan Cipta Cara Padu; and Jesuit Refugee Service (Latin America and the Caribbean).
} 
the value of informal networks from adult men and women living in the slums and informal urban settlements of the selected case studies (Creswell 2014; Corbin and Strauss 2008). The phenomenological approach is proven to be effective at bringing to the fore the experiences and perceptions of individuals from their perspectives. Therefore, it is good at challenging structural or normative assumptions that persist in vulnerable urban settings (Creswell 2014).

Furthermore, it helps to understand the essence of the phenomenon's experiences (Creswell 2014), in this case, the essence of being a dweller in the slums. The methods employed were primarily in-depth interviews and focus groups, which according to Kvale and Brinkmann (2009) supports significant social relations exploration, In-depth interviews were conducted with residents at the household level (heads of households, both male and female) in the informal settlements of Kibera and Kawangware $(n=44)$. Six focus group discussions were conducted in each informal settlement to explore individual and collective access to opportunities, individual and collective connections to people with power, resources, and influence of relevance to linking capital. Four focus groups were undertaken with women (two with girls), four with men (two with boys), and the other four mixed genders. Mixed group interviews were conducted to assess levels of consensus. Thematic analysis was deployed to analyse the interview and focus group data.

Since the sampling technique employed was judgemental/purposive, the research participants were recruited using gatekeepers (community leaders, village/neighbourhood leaders) and formal and informal networks. The appointments to approach and meet the participants for interviews were made through the NGO local partners' focal persons who then contacted the neighbourhoods' gatekeepers and leaders to nominate the participants for both one-to-one interviews and focus groups. The gatekeepers in each locality were asked to select the participants following the laid down criteria.

\section{Results}

A detailed analysis of the survey data collected in urban slums presents many similarities and significant differences in households' livelihood in Kibera and Kawangware. In keeping with the inclusion criteria, all the 735 respondents were over 18 years of age, and $92 \%$ identified themselves as either the head of household or the spouse of the head of household. Over $70 \%$ of the study respondents were residents in their respective areas for more than 3 years; however, $55 \%$ of respondents from Kibera had lived there for more than 5 years compared to $23 \%$ in Kawangware - suggesting that Kibera is a more mature settlement. The study respondents' mean household size was 3.4 persons with a range of between one and eleven members. Here again, there was a significant difference between the household size in the two study areas. Almost half of the households studied in Kawangware reported having a household size of two or fewer persons compared to less than $25 \%$ in the case of Kibera. At the other extreme, respondents in Kibera indicated that $37 \%$ of households had five or more persons compared to $14 \%$ in Kawangware. Despite these differences, there was no significant difference in the age profiles of household members in both slum areas-both reporting approximately $40 \%$ of households having either one or two children below 5 years old, and both slums reported $2 \%$ of the households having an elderly person over 65 years old. Seventy percent of households studied indicated only one income earner in the household-similar in both slums. Approximately $8 \%$ of households had no primary income earner-12\% in Kibera and only $4 \%$ in Kawangware. Only $20 \%$ of households had two or more income earners with no significant difference between the two slums.

The varied household size and the relatively limited number of income earners account for the high household dependency in both slums and the differences in the selected slums. While there was a relatively high household dependency for the entire population at $45 \%$, the study found that $60 \%$ of Kibera households exhibited high dependency levels compared with $30 \%$ in Kawangware. An analysis of the primary income earner's education levels indicated that more than $90 \%$ had a formal education. Approximately half of the primary income earners had some secondary education, and $10 \%$ had third-level education. Surprisingly, Kibera had significantly higher levels of primary income earners with no formal education (13\% as opposed to 5\% in Kawangware). Still, Kibera also had significantly higher levels of primary income earners with third-level education (13\% compared with $6 \%$ in Kawangware). The study found high levels of illness in both slums with more than half of the households studied, indicating that at least one person had fallen ill 2 weeks before the study. There was no significant difference in levels of sickness between the two slums.

Both slum areas reported high usage of livelihood coping strategies $-63 \%$ of households indicated that they had used more than 6 of the 18 identified coping strategies in the 4 weeks prior to being surveyed. There was no significant difference in the number of coping strategies employed; however, there were inter-and intra-slum differences in households' types of coping strategies. A detailed analysis of the 18 coping strategies identified in the study suggests that they be further categorised into two groupings: absorptive coping strategies; and adaptive coping strategies. Examples of absorptive coping strategies (AbCS) in this study include reducing meal portions; skipping meals; reducing the variety of food consumed; consuming 


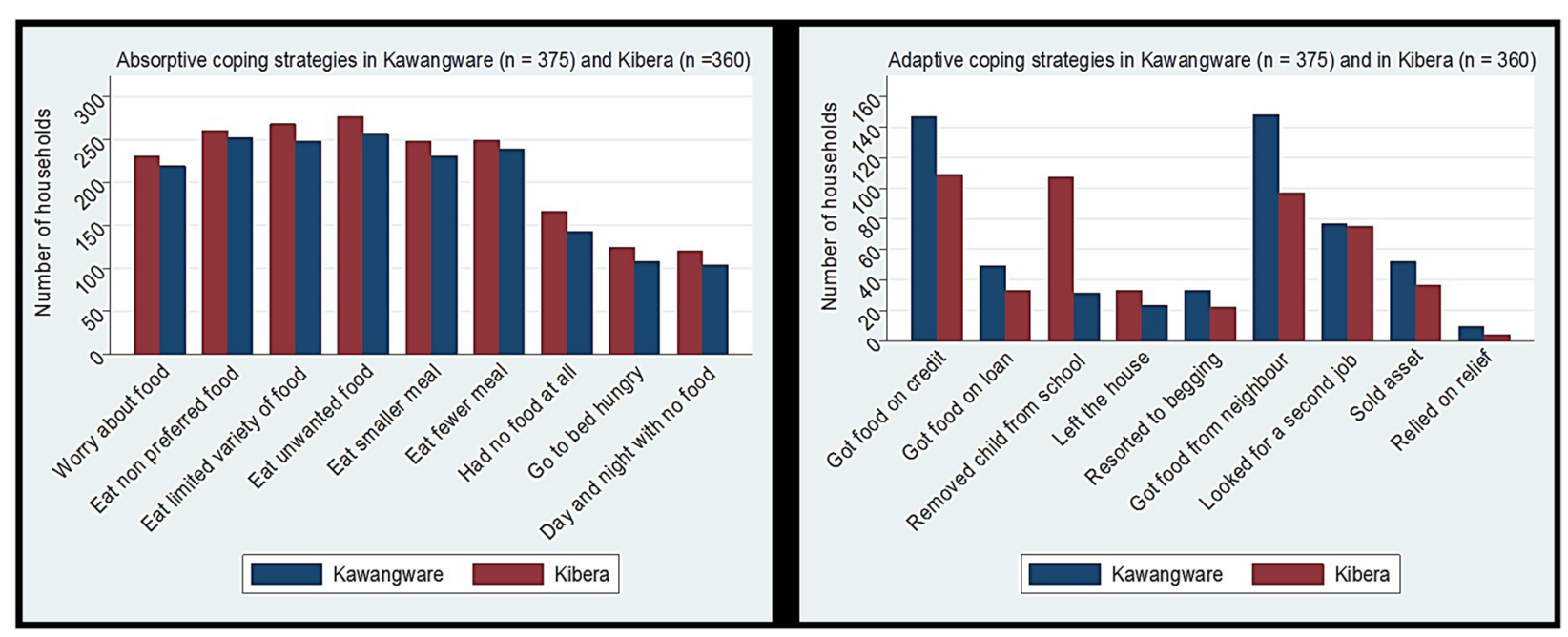

Fig. 3 Use of absorptive and adaptive strategies in the two slums

unfavourable foods; not eating for full days; and going to bed hungry (Fig. 3). Examples of adaptive coping strategies (AdCS) identified in this study included: sourcing food relief; seeking food on credit; seeking loans or financial support to buy food and essential household items; removing children from school; removing a person from the household due to food shortages; begging for food or money; seeking food or money from friends or neighbours; taken on additional work/employment; and selling off assets to get money to buy food or essential household items (Fig. 3).

Figure 3 shows that $80 \%$ of the households $(77 \%$ in Kawangware compared with $83 \%$ in Kibera) absorbed shocks and stresses by changing their food diets because they had no money to buy food 4 weeks before the study. There is a striking similarity in the type and number of the AbCS used by the households across the two study slums at the survey time. A high proportion of the households, more than $67 \%$ in Kawangware and up to $76 \%$ in Kibera resorted to eating unwanted food, eating a limited variety of food, eating non-preferred food, and eating smaller portions of food in that order when they had no money or resources to sustain the household. Spending a night and day without food is the least used AbCS in the two slums (29\% in Kawangware in contrast with Kibera, which was 34\%). Yet there is no indication in the data that people were undergoing particularly significant stress or shock. This implies that people are engaging in strategies to absorb and adapt to shocks and stresses as a constant feature of their livelihoods.

Moreover, Fig. 3 shows that two-thirds of the households (67\% in Kawangware similar to Kibera-66\%) had to make adjustments in the way they survive. Receiving food from a neighbour, buying food on credit, and removing children from school due to lack of money to buy food was the most used AdCS across the two slums in the 4 weeks before administering the survey. A closer look shows that for Kawangware, asking the neighbour $(40 \%)$ to help in times of need was the most popular AdCS followed by obtaining food on credit (39\%) and looking for additional employment (21\%). For Kibera, getting food on credit, withdrawing children from school, receiving food from a neighbour and looking for second employment is the most commonly employed AdCS at a frequency of up to $30 \%$ of the households. However, removing children from school seems not to have the same level of incidence of the households-up to $30 \%$ in Kibera and only $8 \%$ in Kawangware. These differential outcomes necessitated a further examination of the data to determine the presence, direction, and strength of the relationship between social capital and the use of AdCS. The results of this examination are presented in Table 1.

The head of the household is the family member acknowledged by the other household members as having central authority and responsibility for household affairs either by his/her age or standing in the house as the primary income earner and one that takes major decisions. He/she is the key decision-maker in the household. Overall, $79 \%$ of the total sample across the two settlements were male-headed households (89\% in Kawangware compared to $69 \%$ in Kibera). The results of the regression analysis as can be seen in Table 1 , showed that there is a very weak positive relationship between sex of household head and the use of adaptive coping strategies in Kawangware and no correlation 
Table 1 Effects/association of social capital on/with coping strategies in Kawangware and Kibera slums

\begin{tabular}{|c|c|c|}
\hline \multirow[t]{3}{*}{ Social capital determinants (independent variables) } & \multicolumn{2}{|c|}{ Use of adaptive coping strategies } \\
\hline & Kawangware & Kibera \\
\hline & Coefficients $^{\mathrm{a}}(95 \% \mathrm{Cl})$ & Coefficients (95\% Cl) \\
\hline \multicolumn{3}{|l|}{ Sex of household head } \\
\hline Female (reference category) & 1 & 1 \\
\hline Male & $0.141(-0.38,0.66)$ & $0.058(-0.28,0.39)$ \\
\hline \multicolumn{3}{|l|}{ Household-level dependence } \\
\hline Low (reference category) & 1 & 1 \\
\hline High & $0.229(-0.21,0.67)$ & $0.67(0.30,1.04)^{* * *}$ \\
\hline \multicolumn{3}{|l|}{ Number of income earners in the household } \\
\hline None (reference category) & 1 & 1 \\
\hline 1 person & $-0.311(-2.18,1.55)$ & $-1.142(-3.28,1.00)$ \\
\hline $2+$ people & $-0.698(-2.61,1.21)$ & $-0.71(-2.87,1.44)$ \\
\hline \multicolumn{3}{|l|}{ Illness in the household } \\
\hline None (reference category) & 1 & 1 \\
\hline 1-2 people & $0.311(-0.01,0.63)$ & $0.679(0.37,0.99)^{* * *}$ \\
\hline $3+$ people & $0.585(-0.39,1.56)$ & $1.38(0.73,2.03)^{* * *}$ \\
\hline \multicolumn{3}{|l|}{ Interpersonal relationship } \\
\hline Good (reference category) & 1 & 1 \\
\hline Poor & $0.265(-0.07,0.60)$ & $0.328(-0.01,0.67)^{*}$ \\
\hline \multicolumn{3}{|l|}{ Primary income earner education } \\
\hline Not educated (reference category) & 1 & 1 \\
\hline Primary & $0.24(-1.46,1.94)$ & $0.849(-1.15,2.85)$ \\
\hline Secondary & $-0.104(-1.80,1.59)$ & $0.526(-1.46,2.51)$ \\
\hline University & $-0.14(-1.94,1.66)$ & $0.08(-1.95,2.11)$ \\
\hline \multicolumn{3}{|l|}{ Source of income } \\
\hline Other (reference category) & 1 & 1 \\
\hline Casual labour & $0.097(-0.88,1.07)$ & $0.998(0.10,1.89)^{*}$ \\
\hline Business & $-0.227(-1.35,0.89)$ & $0.801(-0.21,1.81)$ \\
\hline Monthly salary & $0.028(-0.95,1.00)$ & $0.676(-0.24,1.59)$ \\
\hline Number of observations & 375 & 360 \\
\hline Prob $>F$ & 0.000 & 0.000 \\
\hline$R$-squared & 0.1487 & 0.2558 \\
\hline Adj $R$-squared & 0.1032 & 0.2142 \\
\hline
\end{tabular}

Source: IDSUE Baseline Survey, 2015

Note: $\mathrm{Cl}$ (confidence interval in parenthesis); ${ }^{*} p$-value $\leq 0.05 ;{ }^{* *} p$-value $\leq 0.01$; ${ }^{* * *} p$-value $\leq 0.001$; ref reference category ( $\mathrm{A}$ "reference category" is a response identified as a category of comparison for the other categories. By default, Stata uses the alpha-numerically first category as the reference category, for example "a" with letters, " 0 " with numbers. For the analysis of this study the reference category was assigned a value of 1 to allow Stata to pick the preferred category as a reference for comparison.)

${ }^{\text {a }}$ Coefficient of correlation is a method that examines the relationship between two variables. It examines three aspects: presences or absence, direction and strength of the relationship. In general, coefficients range from -1 to +1 . A zero value indicates absence of relationship. The closer the coefficient is to 1 ( +1 or -1 ), the stronger the correlation and the closer it is to 0 the weaker the correlation. The sign stands for direction, when positive $(+)$ it means that the variables change in the same direction while negative sign (-) means that the variables move in an opposite direction. In summary, very low correlation has a coefficient value under 0.20 , low correlation has a coefficient value between 0.21 and 0.40 , moderate correlation has a coefficient value between 0.41 and 0.70 , high correlation has a coefficient value between 0.71 and 0.91 , and very high correlation has a coefficient value over 0.91 (for more details, see Sarantakos 2005 page 377 )

between sex of the household head and the number of adaptive coping strategies used in Kibera. However, a closer examination of the data found that in Kibera female-headed households are three times more likely to resort to begging, have a household member leave, or sell household assets to obtain money to buy food. In
Kawangware, by contrast, there was no significant difference between male and female-headed households in the type of adaptive coping strategies used.

The second association investigated in the study was household-level dependence with the use of adaptive coping strategies. Dependence in this study's context 
is understood as the age-population ratio of those typically not in the labour force (the dependent persons aged 0 to 18 and $65+$ ) and those usually in the labour force (the productive ages of between 18 to 64). Dependency ratio is used to measure the pressure on the productive population. Unsurprisingly for Kibera, the regression analysis showed a higher statistically significant association between the household level dependency and use of adaptive coping strategies than in Kawangware, which was very low and not significant. However, in both slums, more than $70 \%$ of the households with high household level dependency used one or more adaptive coping strategies. As expected, the data showed that in both slums each adaptive coping strategy was employed by more than $70 \%$ of households with a high number of dependents in their households in the 4 weeks before administering the survey.

The third association examined was the number of income earners in the household and adaptive coping strategies in both slums. The number of income earners is the total number of people in the household that were on regular salary (full-time or part-time employment), had a business, or engaged in casual labour at the time of the interview. The data showed overall $72 \%$ of the households had at least one income earner. However, Kawangware had a much higher percentage (79\%) than $64 \%$ in Kibera of the households with at least one income earner. In both slums, less than $20 \%$ of the households had two or more income earners. Nevertheless, the regression analysis showed a negative association (very strong in Kibera and moderate in Kawangware) between the households with one or more income earners and adaptive coping strategies. As expected, most adaptive coping strategies such as getting loans to buy food, purchasing food on credit, and selling assets were employed by more than $85 \%$ of the households across the two slums with one or more primary incomes in the 4 weeks before the administration of the survey.

The fourth association was between illness in the household and the use of adaptive coping strategies. The data showed that more than half of the households across the two study areas reported having one or more illnesses in the household 2 weeks before administering the survey. More than $80 \%$ of them used one or more adaptive coping strategies. The regression analysis results showed that for Kawangware, there was a moderate association between the presence of illness in the household and the use of coping strategies. This contrasts sharply with Kibera, where a positive and very strong significant association between the presence of illness in the household using adaptive coping strategies was found. This implies that for Kibera, people are more likely to use more adaptive coping strategies if there is an illness in the household. The data showed that the use of each household's adaptive coping strategies with illness in households was in the range of 50 to $70 \%$ of households.

The association of the primary income earner education in the household using adaptive coping strategies was also examined. Access to education is considered as part of an individual or collective access opportunities. More than $70 \%$ of those who had no education or had primary as the highest level of education across the two slums used one or more coping strategies. Only half of those who had third-level education used one or more coping strategies. The regression analysis results showed that for Kawangware, there was a very weak negative association between primary and secondary school categories of education and the use of adaptive coping strategies. For Kibera, the regression results showed a strong association between education and adaptive coping strategies, especially for primary and secondary education levels. Only third-level education proved to have similar results of very weak association across the two slums. This implies that households with primary income earners who attained third-level education are less likely to use more coping strategies. Expectedly, in both slums, most of the adaptive coping strategies were used primarily by those who had primary or secondary school level of education compared to those with no education and those with third-level education. For example, none of the households that had a primary income earner with no education or third-level education removed children from school in Kawangware.

The study also considered the association between a household having a regular income source with adaptive coping strategies. Regular income is understood for the survey as the household having a regular monthly, weekly, or daily salary or income from a stable business. It does not include those whose livelihood is dependent on casual labour, Jua kali, scavenging, remittances, and hustling. In this case, business means a person's regular occupation, profession, and trade-selling goods and services. The persons can be found the following day at work, e.g. a shop, Kibanda ya mboga (vegetable stall), etc. The data showed that Kawangware had a higher percentage $(61 \%)$ of those on regular income than around $40 \%$ in Kibera. A closer examination of the data showed that the households with no regular income source in Kibera were twice as likely as those with a steady income to use one or more adaptive coping strategies. This is again in sharp contrast with Kawangware, where the households with regular income were twice as likely to use one or more adaptive coping strategies. Unsurprisingly, the regression analysis results showed a very weak association between source of income and use of adaptive coping strategies for Kawangware in sharp contrast with Kibera where a very 
strong association between source of income and use of adaptive coping strategies was found. A cross-tabulation of the source of income and use of adaptive coping strategies showed that in Kawangware each of the adaptive coping strategies used by more than half of the households reported having a regular income source (business or monthly salary). Again, quite contrary results were observed for Kibera. Most of the adaptive coping strategies were resorted to a lesser extent, indicating that most households with no regular income opted for adaptive coping strategies.

The follow-up FGDs and in-depth interviews provided the opportunity to analyse further the nature of the coping strategies employed in each of the two communities. The participants suggested that vulnerable households rely on relatives, neighbours, and friends, especially those from the same ethnic group for support. It also demonstrates high levels of "trust" within the informal settlements. As recounted by one participant, this is the trust of "[...] someone in the family, ... parent or brother, one whom I know cannot refuse to help me when I am in trouble" (FGD, 12.06.2018). When asked whom they would contact in times of need, a participant said they would "tell a relative or a friend that the children are sleeping hungry, and the relatives/friends would help" However, there is a norm which must be observed to maintain this exchange; those who are helped must in turn help: "If you think you will be helped because you are known yet you do not help others, it will be hard" (FGD, 20.06.2018). Another condition is not to engage in gossip, "I will go to the neighbour for help on condition they are not people who gossip and should be someone with a good heart" (FGD, 12.06.2018; IDI, 5.06.18). Some participants opined that considering the insecurity of the two informal settlements' livelihoods, there is no way one can survive on his/her own unless that person reciprocates. One participant (IDI, 5.06.18), for example, stated:

"You have to take care of your family first, but if you have a sick neighbour, you help each other... if your neighbour is arrested, we follow up on the case."

Some participants contended that they would only confide with a trusted relative concerning their problems. This dependency on close relatives for help places additional pressure on neighbouring households and leads to the use of more and more coping strategies. These findings suggest that trust and reciprocity norms contribute positively to the socio-economic functioning of informal urban settlements.

It was also evident from the qualitative interviews that slum dwellers who have better links to people with power and resources had better access to opportunities. Most participants argued that many people with authority, influence, and resources often provide opportunities to relatives, friends, and colleagues with the same ethnic or tribal background. Other participants detailed how senior citizens that have, for example, worked for over 30 years ensure they hand over their positions to their children and other relatives. Furthermore, another participant claimed to be aware of an influential person whom whenever he/she is informed of job opportunities, he/she then take people never seen, the last thing to hear is that the vacancies have been filled (FGD, 12.06.18). Another participant asserted that he went to look for a job with a friend, both handed in their Curriculum Vitae, did an interview successfully. However, they were asked to pay 30 thousand Kenyan shillings each; his friend phoned his Aunt, asked for 60 thousand shillings, paid, and got the job, while the poorer man failed to get the job (FGD., 12.06.18). Those who do not have access to better jobs work in the Jua kali industry, especially men. Women tend to engage in small business, laundry being the most common. The income generated is used to cover the cost of food, school fees, rent, medication, water, and other household necessities.

The baseline survey provided limited data of relevance to bridging social capital. However, the study findings indicate that at least some of the surveyed informal settlement dwellers participate in local initiatives and are members of merry-go-round associations. The qualitative data revealed the role such organisations have in securing means and sources of livelihood. The proportion of informal settlement dwellers who participate in social clubs, youth groups, and other local institutions is high, especially in Chamas ${ }^{7}$. Whenever people have financial difficulties, they commonly go to Chamas to borrow money or materials (IDI, 22.06.19):

"We normally meet here though we have not formally registered the group, its fundraising group ... it has been two years, and we normally meet in the second week of the month ... we meet to help one another..."

In such community gatherings, apart from money, the informal urban settlement dwellers also share resources such as food, clothes, and kitchenware. Some

\footnotetext{
Chama is an interpretive in vivo code. The Kenya Association Investments Group describes Chama (Kiswahili for group) as "any collection of individuals or legal persons in any form whatsoever including but not limited to: societies registered under the Societies Act, Partnerships and Limited Liability Companies, whose objective is the pooling together of capital or other resources with the aim of using the collated resources for investment purposes." Though still predominantly patronized by women, Chamas are now frequented by boys, girls, men and are now being established for different kinds of sharing purposes including money, food items, kitchen ware and clothes.
} 
organisations working in Kibera have facilitated the formation of co-operative social groups where the members invest small sums of money. The money is then lent out to the members at a low-interest fee whenever they have problems. Thus, these groupings serve as micro-finance lending spaces and associations where people help each other during funerals and weddings. However, membership in some Chamas is by tribal affiliation. The Luhyas, Kisii, Kikuyus, Luos each have their groups. Some of the women's groups access soft loans from organisations like the Kenyan Women Enterprise Fund and invest in small businesses. The income is used to meet households' basic needs. This indicates that having beneficial connections to people with power and resources could help to minimise the use of coping strategies. If such connections could help secure better livelihoods, it can lead to better access to resources and improved capacities in slums.

Even though slums are believed to be places where there is enormous precariousness of livelihoods, a good number of the households reported to have not used any of the coping strategies, whether adaptive or absorptive, in 4 weeks before the administration of the survey. Eighty-seven households (12\%) out of the total sample drawn from the two study areas reported not to have employed any of the coping strategies in the 4 weeks before the survey. This was an interesting result considering the need to build capacities of the people living in slums. The findings show a significant similarity across the two slums in those households which had a primary income earner with a third-level education, had no illness in the family, or had a regular source of income were most commonly found not to use either AbCS or AdCS. However, dwelling occupancy mode had a significant influence - it could help determine if a household can or cannot use any coping strategies but only for Kawangware. Overall, the frequencies are higher for Kawangware than in Kibera. This merits further exploration to determine the underlying reasons.

\section{Implications for humanitarian and development aid efforts}

The findings confirm the conclusions of previous research studies and the argument that social capital plays a crucial role in addressing the challenges faced by people living in low-income areas and vulnerable urban settings (Aldrich et al. 2020; Amendah et al. 2014; Gallaher et al. 2013; Vervisch et al. 2012; Dean et al. 2011). However, this study has demonstrated in a disaggregated manner how bonding, bridging, and linking social capital affects livelihoods and the use of coping strategies in informal urban settlements. The study has identified an essential element concerning coping strategies, whereby people living in slums use their absorptive and adaptive capacities to deal with everyday stresses and shocks. The use of absorptive and adaptive coping strategies shows that people first use existing capacities before making the necessary adjustments in their livelihoods to deal with everyday problems. Aid actors can and should build on these capacities while focusing on interventions that can transform people's lives in slums. Aid organisations need to monitor how slum dwellers use coping strategies. Otherwise, any crisis faced may tip households into opting for more negative coping strategies. Considering the nature of the two sets of coping strategies, one would tend to believe that households first consider AbCS before engaging in AdCS. However, the findings indicate that this is not the case. There was no necessary obvious sequence of moving from one set of coping mechanisms to another as the literature may seem to indicate. Some households did not engage in absorptive coping strategies but did engage in adaptive coping strategies.

The form of social capital available to the household can determine the course of action for coping and the extent to which they would opt for a specific set of coping strategies and particular type under each set of the coping strategies. The findings indicate that substantial bonding capital is necessary at the household and neighbourhood levels for survival in times of need. Vulnerable people rely firstly on their relatives, whether close or distant in spatial terms, and secondly on their neighbours to cope with stress and shocks in which family, friends, and neighbourhood level interactions play a crucial role. The positive and significant association between bonding capital and adaptive coping strategies means that households in slums with strong connections with family members, relatives, friends, and neighbours can absorb and adapt to the shocks and stresses. This is contrary to the findings of other studies that contend that when people live below the poverty line, they may have no available resources to share (Aldrich et al. 2020). This study's findings show that people share whatever little they have with relatives, friends, and neighbours in times of need as long as they can reciprocate.

Nevertheless, such reliance means that bonding social capital leads to both positive and negative outcomes. Outcomes can be positive in the sense that those who depend on their relatives have access to more support to mitigate their vulnerabilities and can be detrimental because the independent relatives, neighbours, and friends have to bear more significant responsibilities and run the risk of being overburdened. Humanitarian and development aid organisations need to pay attention to these differential outcomes since they can have a bearing on the success of efforts to address vulnerabilities. Family and household level ties are suitable for adaptive coping strategies as per the findings especially considering 
that most showed a strong relationship with the number of coping strategies and were statistically significant at $95 \%$ level of confidence. But this could also be problematic if the focus of aid actors is on addressing needs rather than building on communities' capacities. A clear understanding of the existing bonding social capital would help target the right beneficiaries effectively with relevant aid interventions at the household and neighbourhood levels. For example, aid actors, whether local or international, can orientate aid interventions to reduce dependency within households by fostering employment or when administering aid while being sensitive to family structures.

Even though regression analysis was not conducted to ascertain the relationship between bridging capital and adaptive coping strategies, the findings from the qualitative data analysis showed that community groups such as Chamas, ethnic-based associations, church- or mosque-based groups play a vital role in cushioning the precariousness of livelihoods in the informal settlements. However, as with bonding capital, reliance on such groups can lead to positive and negative outcomes. The findings showed that helping relatives and neighbours was the most typical household- and neighbourhoodlevel adaptive coping strategy. People gather to share ideas and financial and material resources, enabling the uplifting of one another in times of shocks and stresses. To that end, actors should be giving more attention to local clubs, associations, organisations, and companies to build bridges that people could rely upon in times of need. It was noted in this study that working with neighbourhood or community level groups could be undesirable in the sense that the requirements for one to become a member can be discriminatory, for example if the primary criterion for one to become a member is ethnicity or religious denomination. Also, the reluctance of authorities to allow people to come together means that there has to be more transparency on how aid actors operate in slum settings. Aid organisations need to balance the need to work with groups, clubs, or associations with the risk of leaving non-members behind. It is essential to bear in mind that the extreme poor tend to have poor networks and have limited access to information and opportunities as basic as belonging to a Chama. They are often left behind in both humanitarian and development aid efforts. ${ }^{8}$

Similarly, linking social capital is imperative for survival mechanisms of people living in slums. It has been recently argued that linkages between individuals and

\footnotetext{
${ }^{8}$ Concern Worldwide, Urban Context Analysis workshop, July 2018, Nairobi, Kenya.
}

societal institutions in informal settlements require a thorough examination to understand the opportunities that may be explored to address an urban vulnerability (Aldrich et al. 2020). The findings confirmed this argument in the sense that the households which did not have connections and any source of livelihood depended on Jua kali, well-wishers, and non-governmental organisations for food and other financial support. Opportunities for jobs or financial resource support may be available, but if the people have limited or no connections then accessing such opportunities, whether individual or in a group, could be challenging. Therefore, aid organisations need to consider the links they are using to reach their aid efforts' targeted clients. Aid organisations need to help build the linkages. This could be achieved by strengthening the existing security, education, finance systems. The focus should be on the communities and the authorities to quell people's anxieties regarding the interventions and aid efforts being implemented in the slums. Otherwise, the efforts may appear to be working well while the actual aid does not address the people's underlying vulnerabilities.

It is important to note that the associations derived in this study were from cross-sectional quantitative data that could not predict causality or the relationships' direction. The quantitative data also had limited data points on bridging social capital to enable the researchers to run a logistic or probit regression analysis. Again, this study has revealed a serious limitation of livelihood baseline surveys that they fail to collect. They do not make an effort to collect sufficient data on relationships that people rely upon to survive in times of stress and shocks. Nevertheless, the study's mixed nature provided a basis for a more grounded description and explanation of the reasons underpinning coping based on the bonding, bridging, and linking social capital determinants.

\section{Summary of key policy recommendations}

The challenge posed by the urban vulnerability is immense and is being compounded by rapid unplanned urbanisation, climate breakdown, and resource pressures. While the realisation that there is a fundamental shift in the landscape of crises to cities is no longer contested, aid actors are grappling with the complexities of adapting their approaches to the urban context. Therefore, the key recommendation is to shift thinking to prevent the apocalyptic predictions of rapid urbanisation and create resilient metropolises. At the core of this change in mindset is a move from viewing people as the problem to facilitating they consider themselves their own best resource in building a better future; in other words, a source of "capital". Aid actors have to acknowledge the complexities of urban social interaction and understand 
how social interaction can constitute "capital" in informal urban settlements.

Donor governments should provide more long-term strategic and sustainable funding for projects, NGOs (non-governmental organisations), and programmes on strengthening existing local social capital. The donor governments should invest primarily in aid programs that build on the existing local structures by strengthening bridging and linking capitals if aid efforts' localisation is to be achieved effectively. Also, there is a need to invest in building the capacities of local neighbourhood associations and other community-level institutions on knowledge and skills and material resources if efforts towards building resilience are to bear fruits. This could include putting in place mechanisms for understanding existing relationships and connections that help people living in vulnerable urban contexts to survive.

This deliberate effort of building social capital should be integral to humanitarian work. The findings indicated that substantial bonding capital is necessary at the household and neighbourhood levels for social security. Vulnerable people rely first on their relatives, whether close or distant in spatial terms, and second on the neighbours to cope with stress and shocks. The findings on the contribution of bridging capital have underscored the vital role of community groups and associations play a vital role in cushioning the precariousness of livelihoods in the informal settlements. The findings reinforced similar findings, for example Aldrich et al. (2020) which confirmed the argument that households which did not have strong linking capital had no secure source of livelihood and financial support. Aid actors should as part of their work aim to strengthen bonding capital through improved household level relations, bridging capital through empowerment of clubs and associations and linking capital through enhanced linkages with societal institutions in order to build the resilience of people living in urban slums.

However, the study has also demonstrated empirically that all three forms of social capital could lead to adverse outcomes. It was evident from the empirical findings that social capital can also be a useful tool for social exclusion, especially in places where there is strong social, economic, political, and cultural apportions in the community. . Gatekeepers could be using these vital links to exclude the deserving clients/beneficiaries of aid efforts. Therefore, the affected population should not use their connections to exclude others from getting access to humanitarian and development aid or any other forms of assistance. Aid organisations should be conscious of how the affected population uses their connections and relationships since social capital has negative and positive outcomes.

\section{Conclusion}

The study's objectives were to identify the main vulnerabilities in informal urban settlements, identify the role of social capital, and propose how organisations should build on existing social capital in their programming. Understanding the implications of humanitarian and development efforts on the existing forms and nature of social capital in the informal settlements is indispensable to building resilience. This study has revealed that household circumstances determine the extent to which households resort to either AbCS or AdCS or both. Shocks or stresses put them at risk of absorbing them by changing household diets or adapting to them by looking for additional employment or selling of households' assets. This study has demonstrated and argued that bonding, bridging, and linking social capital in informal settlements are associated with household coping strategies and livelihoods in general. The findings suggest that where bonding social capital is substantial, households tend to employ a wide range of adaptive coping strategies.

Moreover, needs assessments should focus on the social relationships that people have, such as bonding, bridging, and linking capacities. The data has shown that in slums, there is a considerable predominance of bonding capital which is useful for AdCS. Interventions have to be oriented towards the complex structures that exist in slums and informal urban settlements. Aid actors should take into account the relations and the capacities that people living in slums have to design relevant and appropriate interventions that build on existing relationships and capacities. Thus, aid actors should focus on bridging and linking capital if they are to build the resilience of people living in slums. The NGOs should also be working or selecting the poorest of the poor when conducting needs assessments or baseline surveys. They need to consider the networks of support that people have at household, neighbourhood, and community levels.

Furthermore, the results indicated that due to livelihoods' precariousness, people living in slums rely on their neighbourhood-level connections and utilise local associations to survive. This highlights the need for improved bridging social capital. The study has also demonstrated pragmatically the need for interventions by governments, humanitarian, and development aid actors in informal settlements to understand the existing linking social capital to enhance the targeting of aid efforts. Therefore, NGOs should promote interventions that help build relations instead of ignoring the social infrastructure, which this study has found to be essential for planning and delivering aid programmes. Programmes and projects help build linkages to build 
the bridging capital, for example by working with the local authorities and the local associations like the $\mathrm{Cha}$ mas. NGOs should provide protection and assistance that should be achieved through negotiation by talking to the authorities. This could strengthen linking capital but in such a way that poor people are not rendered more vulnerable to social exclusion and discrimination. Contrarywise, the study has also demonstrated empirically that all three forms of social capital could lead to adverse outcomes if not properly checked and monitored due to the risk of social exclusion-leaving the needy behind. Future research should focus on the association, and causal mechanisms that underpin, the relationship between bonding, bridging, linking social capital determinants, and vulnerability outcomes in urban settings.

\section{Abbreviations}

IDMC: The Internal Displacement Monitoring Centre; IDSUE: Indicator Development for the Surveillance of Urban Emergencies; NRC: Norwegian Refugee Council; UNISDR: United Nations Office for Disaster Risk Reduction; USAID: United States Agency for International Development; WHS: World Humanitarian Summit; FGD: Focus group discussion; IDI: In-depth interview; KII: Key informant interview; SD: Standard deviation; $n$ : Sample size; Cl: Confidence interval; Coef: Correlation coefficients; AbCS: Absorptive coping strategies; AdCS: Adaptive coping strategies.

\section{Supplementary Information}

The online version contains supplementary material available at https://doi. org/10.1186/s41018-022-00115-0.

Additional file 1. Measures of social capital and adaptive coping strategies.

\section{Authors' contributions}

DM developed the initial draft and made changes based on deliberations with co-authors. PG provided the outline and scope of the paper and provided considerable guidance to the lead author in developing the paper. RMD contributed to the writing of the introduction and assisted with the overall writing process. DOO assisted with the acquisition of qualitative data, analysis, and interpretation, and reviewing of the article. $\mathrm{COO}$ assisted with the acquisition of qualitative data and reviewing of the article. All authors read and approved the final manuscript.

\section{Funding}

This article has been written as part of the Preparedness and Resilience to address Urban Vulnerabilities (PRUV) project. The project has received funding from the European Union's Horizon 2020 research and innovation program under the Marie Skłodowska-Curie grant agreement no. 691060.

\section{Availability of data and materials}

The data that support the findings of this study are available on request from the corresponding author, [DM]. The data are not publicly available due to restrictions [e.g. containing information that could compromise the privacy of research participants].

\section{Declarations}

Ethics approval and consent to participate

Ethical approval was obtained for this study, and informed consent of participants was obtained during the data collection.

\section{Consent for publication}

The study respondents provided permission to use the data for publication purposes.

\section{Competing interests}

The authors declare that they have no competing interests.

\section{Author details}

${ }^{1}$ Centre for Humanitarian Action, School of Agriculture and Food Science, University College Dublin, Belfield Campus, Room G-05, Dublin 4, Dublin, Ireland. ${ }^{2}$ Institute of Anthropology, Gender \& African Studies, University of Nairobi, Nairobi, Kenya.

Received: 2 August 2020 Accepted: 16 January 2022

Published online: 12 February 2022

\section{References}

Abdulla, A. MacAuslan, A., Schofield, L. (2011). Towards sustainable vulnerability reduction for Kenya's ultra-poor living in urban slums. International Conference: "Social Protection for Social Justice" Institute of Development Studies, UK 13-15 April 2011.

Aldrich D, Kolade O, McMahon K, Smith R (2020) Social capital's role in humanitarian crises. J Refug Stud

Álvarez EC, Romaní JR (2017) Measuring social capital: further insight. Gac Sanit 31(1):57-61

Amendah DD, Buigut S, Mohamed S (2014) Coping strategies among urban poor: evidence from Nairobi, Kenya. PLoS One 9(1):e83428. https://doi. org/10.1371/journal.pone.0083428

Anderson ER (2011) Technical report: coping strategies index (CSI.) Development. CARE West Bank, Gaza Retrieved 18/03/2019, available at https:// fscluster.org/sites/default/files/documents/care_wbg_csi_technical_ report.pdf

Bardwell W, Ancoli-lsrael S, Dimsdale J (2001) Types of coping strategies are associated with increased depressive symptoms in patients with obstructive sleep apnea. Sleep 24(8):905-909

Beyer L, Chaudhuri J, Kagima B (2016) Kenya's focus on urban vulnerability and resilience in the midst of urban transitions in Nairobi. Dev South Afr 33(1):3-22

Carney D (ed) (1998) Sustainable rural livelihoods. DFID, London

Chambers R, Conway G (1992) Sustainable rural livelihoods practical concepts for the 21 st century, IDS discussion paper 296. I.D.S., Brighton

Chandler D (2014) Resilience: the governance of complexity. Routledge, London

Chhabra S, Falciglia GA, Lee S (2014) Social capital, social support, and food insecurity in food pantry users. Ecol Food and Nutr 53(6):678-692. https:// doi.org/10.1080/03670244.2014.933737

Coleman-Jensen A, Nord M, Andrews M, Carlson S (2011) Household food security in the United States, Economic Research Service. USDA, Washington, DC

Concern Worldwide \& USAID (2014) Indicator development for surveillance of urban emergencies-IDSUE. Year 4 annual research report. Concern Worldwide, Dublin

Cook KS (2001) Trust in society. Russell Sage Foundation

Corbin J, Strauss A (2008) Basics of qualitative research, 3rd edn. Sage, London

Dean W, Sharkey J, Johnson C (2011) Food insecurity is associated with social capital, perceived personal disparity, and partnership status among older and senior adults in a largely rural area of Central Texas. J Nutr Gerontol Geriatr 30(2):169-186

F.A.O (2002) The State of Food Insecurity in the World 2001, Rome

Gallaher C, Kerr J, Njenga M, Karanja N, WinklerPrins A (2013) Urban agriculture social capital, and food security in the Kibera slums of Nairobi, Kenya. Agric Human Values 30(3):389-404

Gibbons P, McDermott R, Maitra S, Herman J (2017) Building on the capacities of crisis-affected populations: from victims to actors. Dev Policy Rev:1467-7679. https://doi.org/10.1111/dpr.12239

Gingerich TR, Cohen MJ (2015) Turning the humanitarian system on its head: saving lives and livelihoods by strengthening local capacity and shifting leadership to local actors. OXFAM America retrieved from https://www. oxfam.org/sites/www.oxfam.org/files/file_attachments/rr-turning-human itarian-system-local-capacity-270715-en.pdf 
Hope KR Sr (2012) Urbanisation in Kenya. Afr J Econ Sustain Dev 1(1):4-26

Jha A, Stanton-Geddes Z, Miner T (2013) Building urban resilience. World Bank, Washington, DC

Kitchen P, Williams A, Simone D (2012) Measuring social capital in Hamilton, Ontario. Soc Indic Res 108(2):215-238

Kumar S et al (2017) Ending violence in childhood: a global imperative. Psychol Health Med 22(1):1-16

Kvale S, Brinkmann S (2009) Interviews: learning the craft of qualitative research interviewing. Sage

Martin K, Rogers B, Cook J, Joseph H (2004) Social capital is associated with a decreased risk of hunger. Soc Sci Med 58(12):2645-2654

Matyas D, Pelling M (2014) Positioning resilience for 2015: the role of resistance, incremental adjustment and transformation in disaster risk management policy. Disasters 39(s1):s1-s18

Maxwell D, Caldwell R (2008) The coping strategies index: field methods manual - second edition. FAO

Meerow S, Newell P, Stults M (2016) Defining urban resilience: a review. Landsc Urban Plan 147:38-49

Misselhorn A (2009) Is a focus on social capital useful in considering food security interventions? Insights from KwaZulu-Natal. Dev South Afr 26(2):189-208

Mpanje D, Gibbons P, McDermott R (2018) Social capital in vulnerable urban settings: an analytical framework. J Int Humanit Action 3(1). https://doi. org/10.1186/s41018-018-0032-9

Mukeku J (2018) Urban slum morphology and socio-economic analogies: a case study of Kibera Slum, Nairobi, Kenya. Urbanisation 3(1):17-32

Natcher D (2015) Social capital and the vulnerability of aboriginal food systems in Canada. Hum Organ 74(3):230-242

Norwegian Refugee Council, Internal Displacement Monitoring Centre (2015) Urban informal settlers displaced by disasters: challenges to housing responses. IDMC and NRC, Geneva

Paliszkiewicz JO (2011) Trust management: literature review. Management 6(4):315-331

Pamoja Trust (2009) Nairobi slum inventory. In: Environment and urbanization, urban studies journal. International Institute for Environment and Development, London Available at https://www.environmentandurbani zation.org/nairobi-slum-inventory. Accessed 6 Mar 2020

Parker E, Maynard V (2015) Humanitarian response to urban crises: a review of area-based approaches. IIED working paper. IIED, London

Rakodi C, Lloyd-Jones T (2002) Urban livelihoods. Earthscan Publication, London

Ramalingam B, Knox Clarke P (2012) Meeting the urban challenge: adapting humanitarian efforts to an urban world. ALNAP, London

Reber AS (1985) Dictionary of psychology. Penguin, New York

Sahler OJZ, Carr JE (2009) Chapter 50 - Coping strategies. In: Carey WB, Crocker AC, Coleman WL, Elias RE, Feldman HM (eds) Developmental-behavioral pediatrics, 4th edn, pp 491-496. https://doi.org/10.1016/B978-1-41603370-7.00050-X

Salkind NJ (2010) Encyclopedia of research design. Sage Publications, London. https://doi.org/10.4135/9781412961288.n85

Sarkar A (2020) Informal water vendors and the urban poor: evidence from a Nairobi slum. Water Int:1-15. https://doi.org/10.1080/02508060.2020. 1768022

Smith SS (2010) Race and trust. Annu Rev Sociol 36:453-475

Swindale A, Bilinsky P (2006) Development of a universally applicable household food insecurity measurement tool: process, current status, and outstanding issues. J Nutr 136(5):1449S-1452S

UNFPA (2015) The state of world population 2015. United Nations Population Fund, New York

UN-Habitat (2011) Global report on human settlements 2011: cities and climate change, Nairobi

UN-Habitat (2016). UN-Habitat III, adoption of the final outcome of the conference, Quito, 17-20 October 2016, A/CONF.226/4

UN-Habitat (2018) Human rights in cities: alternative solutions to forced evictions and slum demolitions - case studies from Africa, Asia, Central, and South America. UN-Habitat, Nairobi

Usfar A (2002) Household coping strategies for food security in Indonesia and the relation to nutritional status. Verlag Grauer, Beuren

Vervisch T, Vlassenroot K, Braeckman J (2012) Livelihoods, power, and food insecurity: adaptation of social capital portfolios in protracted crises-case study Burundi. Disasters 37(2):267-292
Villalonga-Olives E, Kawachi I (2017) The dark side of social capital: a systematic review of the negative health effects of social capital. Soc Sci Med 194:105-127

Wall, I., Hedlund, K. (2016). Localisation and locally led crisis response: a literature review. Local to Global Protection (L2GB). Swiss Agency for Development and Cooperation.

World Humanitarian Summit Secretariat (2015) Restoring humanity: global voices calling for action: synthesis of the consultation process for the world humanitarian summit. United Nations, New York

\section{Publisher's Note}

Springer Nature remains neutral with regard to jurisdictional claims in published maps and institutional affiliations.

\section{Submit your manuscript to a SpringerOpen ${ }^{\circ}$ journal and benefit from:}

- Convenient online submission

- Rigorous peer review

- Open access: articles freely available online

- High visibility within the field

- Retaining the copyright to your article

Submit your next manuscript at $\mathbf{s p r i n g e r o p e n . c o m ~}$ 